satisfactory therapeutic response. The total available evidence suggests that had lower degrees of prothrombin activity been consistently maintained the results might have more closely resembled those of the Anticoagulant Committee of the American Heart Association, ${ }^{2}$ Loeliger and his co-workers, ${ }^{5}$ and Meuwissen and Hart, ${ }^{6}$ Aspenström and Korsan-Bengtsen, ${ }^{7}$ and the results of the U.S. Veterans Administration Long-Term Study, ${ }^{8}$ as well as many other studies both short- and long-term from the British Isles and from other countries.

The Working Party of the Medical Research Council had previously used an average daily dose of $108 \mathrm{mg}$. of phenindione in their study dealing with long-term preventive anticoagulant therapy, which produced favourable effects in several important categories of mortality and morbidity. However, in this study involving acute myocardial infarction the use of the Thrombotest at $10-20 \%$ levels resulted in a serious reduction of approximately one-third in the daily dose to an average of $72 \mathrm{mg}$. This represents a paradox in the principle of anticoagulant therapy. Acute thromboembolic states usually require more active rather than less active treatment when compared with longterm prevention in an otherwise quiescent phase. What this study does confirm is that when levels of activity in the range of $10-20 \%$ by the Thrombotest are used only minor therapeutic effects involving thromboembolic complications can be expected. As with all other potent drugs, one must give adequate amounts of anticoagulants to obtain full therapeutic effects.

It is a matter of great and international concern that clinicians not especially conversant with the problems and the research in this field will assume that the treatment was optimal, and thereby interpret this report as establishing that anticoagulants are ineffective in the treatment of acute myocardial infarction. This conclusion is not warranted -the therapeutic level used was not optimal. -I am, etc.,

\section{S. WRIGHT}

\section{Department of Medicine,} New York City N.Y Nical College,

REFBRBNCES

1 Poller, L., and Loeliger, B. A., Lancet, 1969, 1, 464.

Tright, I. S., Marple. C. D., and Beck, D. F., Myocardial Infarction, 1954, p. 353. New York, Grune and Stratton.
Hilden. T., Iveroen, K., Raaschou, F., and Schwartz, M., Lancet, 1961, 2, 327.

- Seaman, A. J., 'Griswold, H. B., Baume, R. B and Ritzman, $L \mathbb{W}$., peper presented at Annua Meeting of the American Heart Association New York, 1966.

" Loeliger, B., A., Hensen, A., Kroes, F., VanDijk, L. M.," Fekkes, N. 'de Jonge, H', and Hemker. H., C., Acta Medica Scandinavica Meurisen, $182,549$.

Meuwissen, O. J. A. Th., and Hart, H., Inter-
national Society of Hematology Abstracts-XII national Society of Hematology Abstracts-XII
Congress-September 1968, 169 (Abstract.-R Cons)

Aspenström, G., and Korsan-Bengtsen, K., Acta U.S. Vedica Scandinavica, 1964, 176, 563.

the American Medical Association, fournal of the
929.

- Ebert R. V., Borden, C. W., Hipp, H. R. Fournal of the American Medical Association, 1969, 207, No. 12, 2263.

\section{Avulsion of the Upper Limb}

SIR,-Nearly 40 years ago I had a similar experience to that of Dr. Gunn, cited by Dr. Murray Drennan (29 March, p. 843). One Saturday in November I was driving home in the dark from shooting and came across an accident. A woman of about 60, whom I knew well, had been knocked down by a large car travelling fast. The projecting door handle on the near side had caught her right arm and torn it clean off. There was a tag of mangled flesh which was bleeding in small pulsations and the woman was deeply shocked, but the ambulance had been sent for and arrived soon after I did, so that my contribution was merely to tie a piece of string tightly round the pedicle of the tag and send her off to the hospital.

For another twenty years she was a wellknown figure in the village. An active and efficient housewife and a most cheerful and lovable character, she used to boast that her one arm could do better than a good number of younger pairs she knew.-I am, etc.,

Dunmow, Essex.

GeOFFrey BARBER.

SIR,-I have read with interest Dr. I. Barziano's three cases of upper arm avulsion (11 January, p. 118) and the following letters of Mr. J. A. Barclay (15 February, p. 444) and Dr. A. J. M. Drennan (29 March, p. 843). I have in my possession Cheselden's book The Anatomy of the Human Body, published in 1763, which describes the following case history facing an illustration.

"The figure of Samuel Wood, a miller, whose arm with the scapula was torn off from his body by a rope winding round it, the other end being fasten'd to the coggs of a mill. This happened in the year 1737. The vessels being thus stretched bled very little, the arteries and nerves were drawn out of the arm; the surgeon who was first called placed them within the wound, and dressed it superficially. The next day he was put under Mr. Ferne's care at St. Thomas' Hospital, but he did not remove the dressings for some days. The patient had no severe symptoms, and the wound was cur'd by superficial dressings only, the natural skin being left almost sufficient to cover it; which should in all cases be done as much as may be. Above twenty years since I introduced the method of amputating, by first dividing the skin and membrana adiposa, lower than the place where the operation was to be finish'd, the advantages of which are now sufficiently known."

-I am, etc.,

Royal Devon and Exeter Hospital.

Exeter, Devon.

\section{Hypotensive Effect of Propranolol}

SIR,-I read with much interest the paper by Dr. B. N. C. Prichard and Dr. P. M. S Gillam on the treatment of hypertension with propranolol (4 January, p. 7) as well as a previous paper on the same subject (19 September 1964, p. 725).

I have observed a similar phenomenon in rabbits. Propranolol (5 mg./kg./day) administered to rabbits caused a significant drop in systolic blood pressure. The maximum hypotensive effect was observed 5-7 weeks after the onset of administration of propranolol, and hypotension was maintained for five weeks, at which time the experiment was terminated. I would like to suggest the rabbit as a good experimental model, as these results are very similar to those observed in man.-I am, etc.,

Peggy J. Whittington-Coleman. Department of Medicine, University of Mississippi Medical Centre,

\section{Recovery after taking Weedol}

SIR,-Dr. F. Kerr and his colleagues reported a case of Weedol ingestion with recovery (3 August, p. 290). I wish to give the details of three children who ate Weedol (which contains $5 \%$ paraquat) and recovered.

Three children, aged 3, 5, and 9 years, were admitted to hospital on 29 July 1966. They had been found by an older daughter. The 5-yearold was rolling around on the floor holding his abdomen and retching, but had not vomited. The youngest was just sitting very quietly (which was an unusual posture for him) and the oldest, at first quiet, began crying. A canister 4 in. by $1 \frac{1}{4}$ in. $(10 \mathrm{~cm}$. by $3 \mathrm{~cm}$.) marked Weedol lay nearly empty on the floor, just a few granules being left in the bottom of the canister. No signs of granules scattered on the floor. On questioning, it transpired that another little boy who was present had brought the canister to the house and offered it to the children as icing decoration, and the three of them ate most of it between them. The eldest claimed that the youngest had most of it and she and the middle child much less. She said that the canister was full when they got it.

At that time the only reference readily available was Bullivant's report of the fatal outcome of two cases of paraquat ingestion, ${ }^{1}$ but reference to the Edinburgh Poisons Bureau and I.C.I. Research Laboratories suggested that Weedol was not so lethal, there having been two patients who had eaten Weedol and recovered.

The patients were treated by gastric lavage, and by forcing oral fluids. This fluid intake was pushed so well by the nursing staff that all three patients were incontinent. All three patients progressed without complication, though the chest $x$-ray on the smallest child who was supposed to have eaten most of the Weedol was reported as showing "poor aeration at the lung bases." No attempt was made to analyse the urine for paraquat.

I wish to thank Dr. J. B. Borthwick, consultant physician, for permission to publish these cases.

-I am, etc.,

Peel Hospital,
Galashiels, Selkirkshire.

E. Ll. Lloyd.

REFBRBNCES

1 Bullivant, C. M., British Medical Journal, 1966

1, 1372.
Kerr, F., Patel, A. R., Scott, P. D. R., and
Tompsett, S. L., British Medical fournal, 1968 ,
3, 290 .

\section{Hypertension from Cold Remedies}

Sir,-Commenting on hypertension in patients on monoamine-oxidase inhibitor drugs who take sympathomimetics-for example, in cold remedies-Dr. P. M. Humberstone (29 March, p. 846) writes "we do not have any evidence on how long to expect the blood pressure to remain raised in such circumstances."

In our experiments on normal volunteers taking monoamine-oxidase inhibitor drugs ${ }^{2}$ we found rises in blood pressure from single oral doses of sympathomimetics lasted three to five hours. Naturally the height and duration will be influenced by dose, rate of absorption, etc., and may be longer and perhaps less with slow-release preparations.

Blackwell and Taylor ${ }^{2}$ reported that $44 \%$ of 50 patients taking monoamine-oxidase 